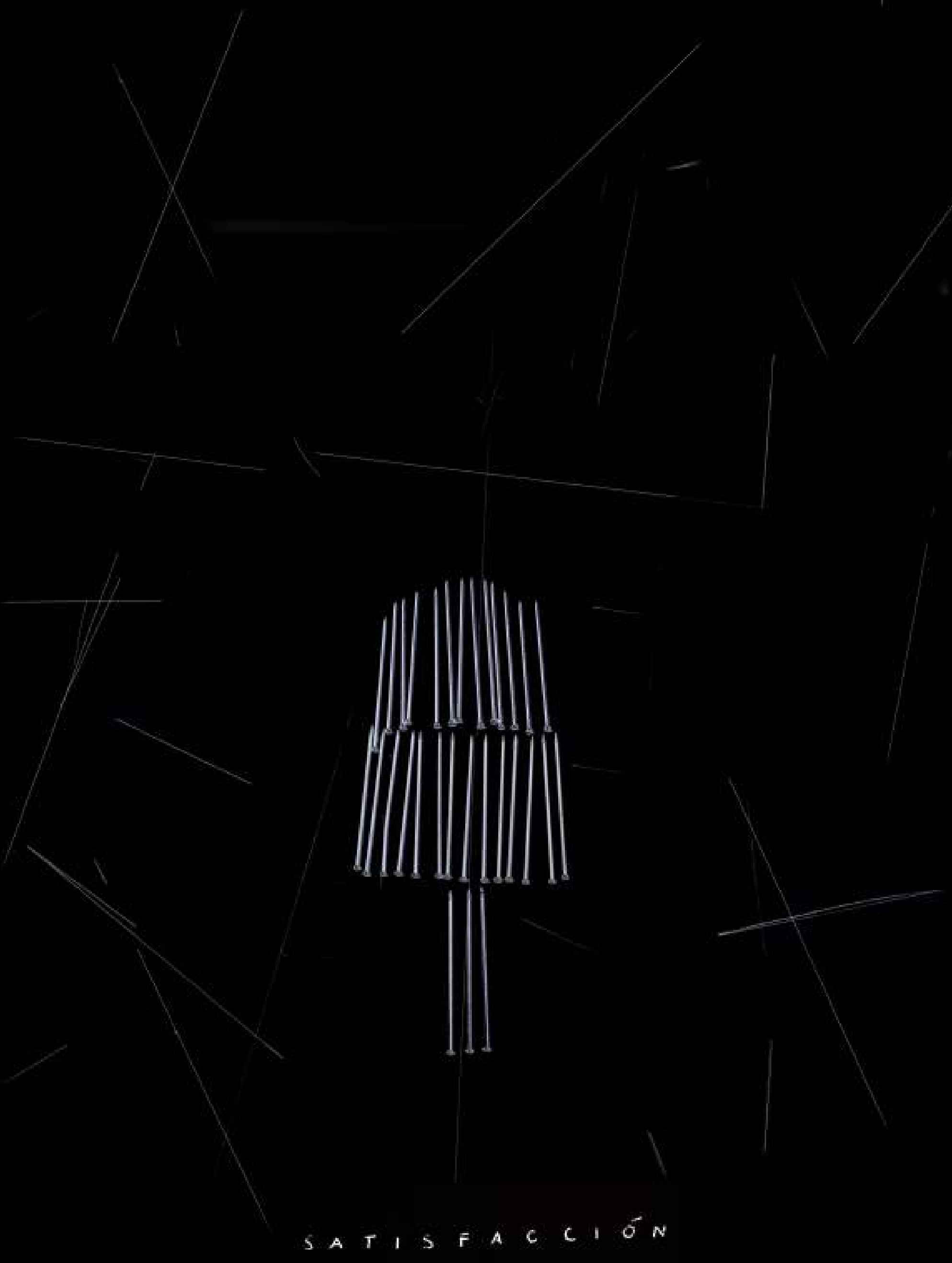


Control percibido,

emociones

y experiencias

satisfactorias

Lozada Cantorán Cindy,

Ortíz Nicolás Juan Carlos,

Cortés López Erika Marlene 


\section{Control percibido, emociones y experiencias satisfactorias}

\section{Lozada Cantorán Cindy}

cindy_lozada@hotmail.com | Investigadora, Creative Robotics Lab, Universidad de New South Wales (UNSW), Sydney, Australia.

\section{Ortíz Nicolás Juan Carlos}

carlos.ortiz@uacj.mx | Profesor-investigador adscrito en la Universidad Autónoma de Ciudad Juárez.

\section{Cortés López Erika Marlene}

profr.erika.cortes@gmail.com | Profesora tiempo completo, Posgrado de Diseño Industrial, UNAM.

Fecha de recepción: 29 abril 2017

Fecha de aceptación: 31 agosto 2017

\section{Resumen}

Basado en la importancia de la satisfacción de necesidades psicológicas humanas, tales como el control percibido, este estudio tiene como objetivo explorar la relación entre el nivel de control percibido del usuario y las diferentes emociones experimentadas durante la interacción con un objeto. De forma tal que los resultados obtenidos aporten información para futuros diseños de productos basados en la satisfacción del usuario y sus necesidades psicológicas. El control percibido está íntimamente relacionado con la satisfacción del usuario y esta puede ser interpretada a partir de las emociones experimentadas durante la interacción. Quizás no es posible identificar cada uno de los factores que influyen el nivel de control percibido que se experimenta en la interacción entre persona y producto, pero sí lo es determinar los factores que detonan emociones específicas y que están ligadas con el control percibido y la satisfacción del usuario.

Palabras clave | control percibido (CP); emociones; satisfacción de usuario; diseño; interacción. 


\begin{abstract}
Based on the importance of universal psychological human needs, such as perceived control, this study aims to explore the relationship between the level of perceived control (locus of control) in user experience and the experimented emotions in the user-object interaction. The results will provide useful information on the design of future products, which aim to fulfil user's satisfaction according to their psychological needs. The concepts of perceived control and user satisfaction are closely related, and the perception of satisfaction within the user can be read through the user's experienced emotions. Even though it is difficult to predict each of the product's characteristics that impact on the perception of control, it was possible to establish the factors that evoke specific emotion. The reported emotions have a strong connection with the perceived control and users' satisfaction.
\end{abstract}

Keywords | perceived control (PC); emotions; user satisfaction; design; interaction. 


\section{Introducción}

A lo largo de la historia del ser humano, se ha reconocido que sentirse en control es importante para el bienestar general de cualquier individuo. Es posible apreciarlo en la literatura, desde la ciencia ficción a lo puramente científico. Epicteto (Filósofo griego, 55-135 A.C.) dijo: "Ningún hombre es libre, si no es dueño de sí mismo". El individuo que percibe poco o ningún control en su vida tiende a sentirse como un pequeño engrane que forma parte de una gran máquina, y expuesto a fuerzas imposibles de controlar (Rotter, 1966).

De acuerdo con diferentes teorías en el campo de la psicología (e.g., Teoría de la autodeterminación), podemos entender el bienestar humano como el resultado de la satisfacción de sus necesidades psicológicas, como son la aptitud, relación o conexión, aceptación, seguridad o control, estimulación, entre otras (Ryan \& Deci, 2000).

A partir de este concepto universal de bienestar, las necesidades pueden ofrecer una guía importante e inspiración para el diseño de experiencias significativas, ofreciendo así diferentes categorías, por ejemplo, la experiencia de conexión o la de aceptación. Es decir, el diseño de experiencias toma como eje central el bienestar humano.

De acuerdo con Hassenzahl y Diefenbacher (2012), las experiencias que se obtienen a través de objetos o servicios difieren enormemente de acuerdo a la necesidad que se satisface. Ejemplo de ello son las aplicaciones que muestran el nivel de esfuerzo personal o éxito en áreas como deportes, nutrición, salud, etcétera; éstas pueden generar experiencias de competencia. Sin embargo, cuando las aplicaciones permiten adicionalmente compartir y comparar datos con otras personas, esto podría llevar de la experiencia de competencia a la experiencia de aceptación o popularidad. Entonces, depende de la necesidad que el diseñador busca satisfacer, que se eliminen funciones aparentemente esenciales. Por ejemplo, el reproductor Mo surgió a partir de la idea de crear un reproductor Mp3 que estimulará la interacción social. La gente agrega sus canciones favoritas y las lleva consigo a reuniones con amigos. Fue diseñado para ofrecer la experiencia de conexión y popularidad, más allá de la simple reproducción de música. Esto tiene un gran impacto en la funcionalidad del producto. 
Aun cuando la mayoría de los reproductores en el mercado cuentan con un display o función para adelantar. Con Mo, estas funciones no están disponibles, ya que siempre reproduce las canciones favoritas de los usuarios, si alguien desea saber el nombre de alguna canción, al menos una persona podrá ofrecer dicha información. Es decir, la ausencia de la pantalla fue resultado de una decisión deliberada para ayudar a conversar, generando también una sensación de popularidad en aquel que conoce la canción (Desmet \& Hassenzahl, 2012).

La percepción de control como necesidad psicológica, sugiere que en una circunstancia determinada es posible ejercer control de manera efectiva, y suficiente para afrontar situaciones, aunque el control real no se llegue a ejercer. El ser humano no necesita poseer control real para beneficiarse de él, la mera percepción es suficiente para aumentar la motivación o estimular el rendimiento (Peterson \& Stunkard, 1992).

El presente estudio surge así de la pregunta ¿qué papel juega el control percibido en la experiencia del usuario?.

El objetivo de este estudio está dividido en dos partes. La primera es establecer la relación entre el nivel de control percibido como necesidad psicológica y las emociones experimentadas durante la interacción objeto-usuario, para poder determinar si existe una correlación entre el nivel de control percibido y el tipo de emoción experimentada por el usuario, ya sea positiva o negativa. La segunda es identificar si existe una correlación entre el nivel de control percibido y la satisfacción general del usuario en la interacción con un producto.

\section{Control percibido}

El concepto de control percibido deriva de la teoría de aprendizaje social de Rotter (1966), la cual sostiene que una persona que piensa que puede tener control de su ambiente también cree que puede controlar su comportamiento. Y de acuerdo con Levenson (1973), existen tres factores o dimensiones que determinan el nivel de control percibido: 1) interno, 2) otros poderosos y 3) el azar. 
El control percibido puede ser definido como la creencia de que el individuo puede determinar sus propios estados internos y comportamientos, para de esta manera influir en su entorno y/o lograr un resultado deseado (Wallston, Wallston, Smith \& Dobbins, 1987). Y es dicho control percibido el que ha mostrado ejercer un papel crucial en la vida del ser humano (Glass \& Singer, 1972; Lazarus \& Folkman, 1984) así como, propiedades que aportan a la inducción de motivación (Kidwell \& Jewell 2010; Skinner, 1996; Sprott, Brumbaugh, \& Miyazaki, 2001). De igual forma, este término ha sido analizado en estudios de mercado, en donde se ha encontrado una relación directa en su influencia tanto en el placer (Hui \& Bateson 1991), el estado de ánimo, la participación (Ward \& Barnes, 2001), la satisfacción (Wathieu, et al, 2002) y el deseo de adquisición (Mathur, 1998).

El control se ha definido como la necesidad de demostrar la propia competencia, superioridad y dominio sobre el entorno. Siendo así, un factor esencial para la satisfacción de diversas interacciones interpersonales (White, 1959).

\section{El nivel de control percibido en la interacción persona-objeto}

La experiencia de usuario va más allá de la facilidad de uso o usabilidad (Pavliscak, 2014; Hassenzahl, 2010; Ortíz-Nicolás \& Aurisicchio, 2011). Se relaciona con motivaciones, actitudes, expectativas, patrones de comportamiento y limitaciones. Se refiere a los diferentes tipos de interacciones que tiene la gente con un producto, lo que sienten respecto a una experiencia y la acciones que esperan llevar a cabo. Las señales correctas sobre la experiencia de usuario suelen ser una combinación de varios factores, por ejemplo: interacciones, percepciones, emociones, etcétera. Las interacciones se refieren a lo que la gente realmente hace, incluyendo clicks, desplazamientos, etcétera. Las percepciones por otro lado son lo que la gente piensa acerca de una experiencia de uso y cómo se sienten al respecto. Es por ello que, si se lleva a cabo el seguimiento tanto de las interacciones como de las percepciones de forma conjunta, éstas tienen el potencial de volverse significativas (Pavliscak, 2014). Una manera de proveer significado y emoción a la experiencia del usuario es mediante la satisfacción de las necesidades psicológicas (Hassenzahl, 2010). 
Se puede decir entonces, que las necesidades psicológicas pueden establecer una guía para diseñar la tecnología desde una perspectiva de bienestar. Por ejemplo, de acuerdo con Sheldon y colegas, un usuario o cliente potencial deberá sentirse en control la mayor parte del tiempo para poder disfrutar o continuar la experiencia con un producto determinado (2001).

Si el control percibido corresponde a una necesidad psicológica que se puede cubrir a través de la práctica del diseño, ¿qué tan importante es el nivel de control percibido en el usuario, para que éste pueda experimentar una satisfacción de uso, así como emociones positivas, durante y como resultado de la interacción?.

Teniendo en cuenta que el control percibido corresponde a una necesidad básica del ser humano o usuario que se refiere a sentirse seguro y en control de su vida en lugar de sentirse inseguro y amenazado por sus circunstancias, es importante ligar a las emociones porque estas colorean la experiencia (Hassenzahl, 2010); al excluirlas, la experiencia carecería de unidad (McCarthy \& Wright, 2007) ya que en esencia ayudan a discernir si la experiencia es agradable o desagradable (Ortíz-Nicolás \& Aurisicchio, 2011). Establecer si existe una relación directa entre la percepción de control y las emociones durante la interacción objeto-usuario, así como identificar los distintos niveles de control percibido y las emociones que en cada nivel son experimentadas permitirá determinar qué tan satisfactoria o insatisfactoria es la experiencia.

\section{Control percibido y emociones}

La teoría cognitiva de las emociones afirma que éstas son una forma de conciencia del mundo, y que ellas están dirigidas de forma intencional con los objetos, además de estar ligadas con los valores de un individuo. Solomon explica que "las percepciones del mundo no son disparadores de las emociones, sino que esas percepciones son activadas o disparadas por medio de las perspectivas y concepciones que constituyen la emoción" $(2004,77)$. Según el autor, la emoción siempre está dirigida a un objeto e implica una intensidad especial, es 
de esta forma que después de la relación con un objeto o persona, es posible decir "me gusta". A partir de dicha relación existen factores que evocan emociones, y dichos factores están relacionados con juicios acerca de los objetos a los cuales se dirigen las emociones.

\section{Teoría de control-valor}

A partir de la interacción con un objeto, cada actividad lograda o satisfactoria conlleva a una serie de emociones que pueden ser experimentadas por parte del usuario; cada una de ellas con base en el control percibido y el valor que el usuario adjudica a cada interacción.

Debido a que las emociones están influidas por valoraciones o evaluaciones, el control percibido también dependerá de las expectativas del usuario. De acuerdo con el valor; ya sea de éxito o fracaso, se han determinado una serie de posibles patrones de tales apreciaciones, así como de las emociones que pueden conllevar cada una de ellas (Pekrun, et al, 2007).

La teoría de control-valor postula que la evaluación del control percibido, así como del valor o importancia atribuida a los resultados permite predecir las metas de logro y las emociones que serán experimentadas. Sugiriendo que los niveles más altos de control percibido y valor "éxito" predicen emociones positivas tales como orgullo, goce y satisfacción, de la misma forma que negativamente es posible predecir emociones negativas como enojo, aburrimiento o vergüenza.

Es decir, la teoría sugiere que las emociones, ya sean retrospectivas, prospectivas o experimentadas durante la actividad, se verán determinadas por diferentes antecedentes de evaluación basados en los valores "éxito" o "fracaso" y control percibido.

Ya que las emociones pueden ser vistas como procesos coordinados dentro de sistemas psicológicos, incluyendo procesos afectivos, cognitivos, motivacionales y expresivos, la teoría de control-valor ofrece un enfoque integral para poder analizar los efectos de las diferentes emociones experimentadas ante la percepción de éxito o fracaso en el usuario. 
Más adelante, en la presentación de resultados del experimento realizado, se ofrece un enfoque más detallado de la teoría control-valor para el análisis de control percibido y emociones durante la interacción objeto-usuario.

\section{Control percibido y experiencia placentera en el usuario}

Dewey explora a la experiencia como algo que no es exclusivamente interno del individuo, sino que está influida por el medio.

En una palabra, desde que nacemos hasta que morimos, vivimos en un mundo de personas y cosas; un mundo que en gran medida es lo que es, en razón de lo que han hecho y transmitido las actividades humanas precedentes. Cuando se ignora este hecho, la experiencia es considerada como algo que ocurre exclusivamente dentro del cuerpo y la mente del individuo (Dewey, 1967, 40).

Este autor habla también del término interacción para referirse a la relación que existe entre el individuo y el medio a través del cual se da una experiencia y propone que dicha relación se da tanto de forma objetiva, como de manera interna o subjetiva; las condiciones objetivas se refieren al medio y las internas, a lo que está en el interior del individuo, es decir sus percepciones.

El concepto de experiencia desde el campo del diseño, parte de la interacción humana con un objeto, producto o incluso servicio (material o inmaterial), en donde dicha interacción ha sido planeada y conlleva un fin. La interacción como menciona Margolin, tiene dos dimensiones: una operativa y una reflexiva. La dimensión operativa implica el modo en que utilizamos los productos, y la dimensión reflexiva, a la manera en cómo se piensa o se siente acerca de un producto, así como del significado que se le asigna. Estas dimensiones funcionan de manera conjunta, ya que no se puede usar un producto sin considerar lo que significa su uso para el individuo mismo $(2002,63-64)$. 
Al revisar diversos modelos de experiencia de usuario se estableció que la mayoría de los autores reconoce que una experiencia es subjetiva, ya que se ve influenciada por sentimientos, gustos y pensamientos que son resultado del estilo de vida personal, y que, como consecuencia de ello, una persona vive su propia experiencia y determina lo significativa que pueda llegar a ser. De igual forma, la experiencia también posee un lado consciente debido a que el usuario es capaz de percibir sus sentimientos y sensaciones a partir de la interacción con un producto (Ver Ortíz-Nicolás, 2014). De tal manera, las emociones generadas a partir de una experiencia son de gran importancia, ya que regulan a la experiencia misma y a través de ellas las experiencias pueden ser categorizadas como satisfactorias o insatisfactorias.

Existen pruebas de que el aumento de la percepción de control puede contribuir a experiencias agradables. Hui y Bateson (1991) han proporcionado evidencia respecto al rol del control percibido y la importancia de su influencia en las respuestas emocionales derivadas de una experiencia de servicio. Así mismo, Langer y Saegert (1977) demostraron que la satisfacción puede ser el resultado emocional de acuerdo con las variaciones en la percepción de control. Quizás el hallazgo más importante de Hui y Bateson sea que ellos afirman que "el concepto de control percibido puede contribuir a explorar distintas formas de crear una experiencia de servicio más agradable" (181).

\section{Experimento control percibido-emociones}

Para llegar al objetivo de esta investigación, determinar la relación entre el nivel de control percibido y el tipo de emociones experimentadas durante la interacción objeto-usuario; así como, las implicaciones de dicha relación en la satisfacción del usuario, el estudio se desarrolló en cuatro etapas presentadas en la Figura 1. 

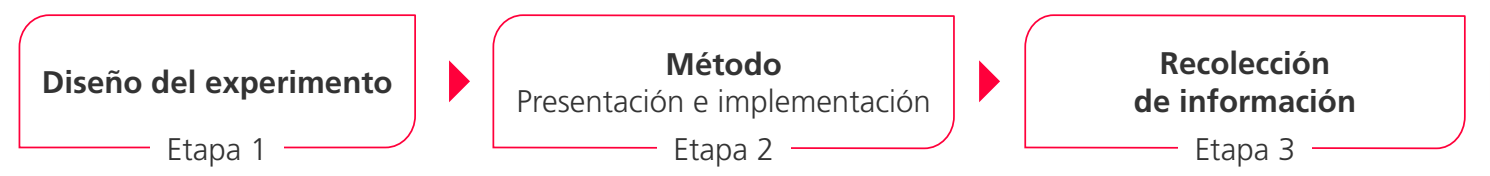

Resultados
Etapa 4

Figura 1. Cuatro etapas para cumplir el objetivo del artículo.

Diseño del experimento

Para cumplir el objetivo de este estudio se resolvieron cuatro retos clave, los cuales se mencionan a continuación:

1 Medición del nivel de control percibido en la interacción objeto-usuario.

2 Evaluación de factor emocional.

3 Identificación de factores básicos que evocan emociones en la interacción persona-producto.

4 Análisis de resultados para determinar la relación entre el control percibido y emociones.

\section{Medición del nivel de control percibido en la interacción objeto-usuario}

De acuerdo con la escala de Locus of Control de Levenson (1973) existen diferentes factores que permiten establecer el tipo de percepción que el ser humano tiene respecto al mundo. Basándose en el razonamiento de que las personas que creen que el mundo es caótico o impredecible, piensan y se conducen de manera diferente que aquellas que creen que el mundo es ordenado o bajo control. Para determinar el nivel de control percibido en la interacción objeto-usuario se realizó una adaptación del cuestionario de Levenson. Con base en una amplia investigación sobre el control percibido y sus implicaciones durante la interacción objeto-usuario, cada uno de los ítems de la escala implementada fue reestructurado con el fin de propiciar información necesaria para poder evaluar el nivel de control percibido en el usuario. El cuestionario de nivel de control percibido cuenta con veintiún ítems en una escala de valores del uno al cinco. La Figura 2 muestra un ejemplo de la adaptación llevada a cabo. 
- When I get what I want if's ususily because im kicky

(Licetes of control sceles, Leverson, 1973)

- Logré usar al producto porrque tuve buerse suerle.

Usar el producto de forma satisfactoria ol producto dopondió de mi capacidad. Para usar el producto es necesario estar con otras personss que lo usen también. Debo ser un experto para poder usar el producto.
Figura 2. Adaptación de la escala de control percibido para la interacción objeto-usuario.

\section{Evaluación del factor emocional}

La Teoría de control-valor: control, valores y emociones de logro, de Pekrun (2006), establece patrones que ligan el nivel de control percibido durante una actividad y después de ella, así como el valor del individuo, con emociones experimentadas, en otras palabras, existe un antecedente directo entre el control y las emociones. Para estudiar dicha relación en este estudio recurrimos a la Teoría Cognitiva de las emociones, que sugiere que éstas están dirigidas de forma intencional a los objetos o personas, y además están ligadas a los valores de un individuo. $Y$ es a partir de apreciaciones o evaluaciones, que se experimenta una emoción (Arnold, 1960; Hernández, 2009; Solomon, 2004). Por ejemplo, si el producto funciona como una persona espera, generalmente experimentará emociones positivas; de lo contrario experimentará emociones negativas. Así la teoría cognitiva establece que es posible identificar lo que causa la emoción a partir de su intencionalidad. En el ejemplo anterior el producto es la causa de experimentar una emoción, aunque también podría ser estimulada por otras personas o el propio ser.

Para llevar a cabo el estudio se eligieron seis emociones a partir del set identificado por Desmet en países europeos (2012). Además, comparamos esa información con datos recabados en el campo de las emociones en relación persona-objeto en el contexto mexicano (Ortíz-Nicolás \& Hernández-López, 2008; Ortíz-Nicolás, 2017). Las emociones que se implementaron en este estudio son tres positivas: alegría, confianza, goce. $Y$ tres negativas: desconfianza, aburrimiento, frustración. 
Una vez que se seleccionaron las emociones, se estableció el método para obtener la información de este factor en la interacción persona-objeto. Considerando que era fundamental entender a profundidad esta dimensión, es decir identificar las emociones que un producto estimulaba no era suficiente, necesitábamos entender por qué una persona experimenta emociones específicas a partir de un producto. Se seleccionó un método cualitativo propuesto por Ortíz-Nicolás (2017). En este método, los nombres de las emociones se imprimen en tarjetas y el participante elige todas aquellas que experimentó durante la interacción con un producto en específico. Enseguida, cada participante explica verbalmente las razones por las cuales experimentó tales emociones.

\section{Relación entre el nivel de control percibido y las emociones}

Analizaremos los resultados a partir de una correlación estadística, una técnica que permite indicar si dos variables están relacionadas o no, donde un cambio en una de las variables estará acompañado de un cambio en la otra variable. Dicha correlación puede ser negativa o positiva.

Para determinar si existe relación entre el nivel de control percibido y la satisfacción general del usuario al interactuar con un producto se realizará una prueba One-way ANOVA de correlación entre dos variables (cuantitativa — control percibido- y cualitativa —emociones-). El análisis de resultados de dicha prueba permitirá identificar si existe o no correlación entre la variable nivel de control percibido y la variable tipo de emoción. La posible correlación entre el nivel de control percibido y emociones podrá servir como guía para determinar el nivel de satisfacción en el usuario, así como los factores que lo afectan.

Una vez que se resolvieron los cuatro retos clave fue posible continuar con el diseño del método para cumplir el objetivo de este estudio. A continuación, se explica detalladamente en qué consiste dicho método, sus características y alcances esperados, los parámetros y bases teóricas para la selección y evaluación del producto utilizado, la implementación del método, así como sus posibles fallas. 


\section{Método de estudio}

Este método se diseñó para determinar el nivel de control percibido en la interacción con un producto u objeto, así como las emociones experimentadas. Es un método mixto que consiste en la aplicación de una escala de valor para determinar, primero, el nivel de control percibido (muy alto, alto, medio, bajo, muy bajo); después, el tipo de emociones experimentadas, en voz de los participantes y por medio del uso de tarjetas. De esta manera, se identificarán cualitativamente los factores que evocaron ciertas emociones y su relación con el nivel de control percibido. El estudio siguió un procedimiento interindividual. La mitad de los participantes fueron asignados al grupo de control y la otra mitad al experimental.

\section{Implementación del método}

\section{Participantes}

Cuarenta y dos personas sin previo conocimiento del objeto participaron en este estudio (veintiún hombres y veintiún mujeres). La mayoría de los participantes eran estudiantes de posgrado y su edad estaba entre veinticinco y treinta y cinco años ( $M=28.39$; DS: 3.73). Cada participante fue reclutado de forma individual y aleatoria, siguiendo los criterios necesarios y discutidos anteriormente. La mitad de los participantes interactuaron con el estímulo Buddha Machine negro (Grupo de control) y la otra mitad interactuó con el estímulo Buddha Machine rojo (Grupo Experimental). Ver Figura 4

\section{Estímulo}

Un criterio de selección del estímulo fue el nivel de control sobre el objeto, después de un análisis que incluyó a varios productos se escogió al producto Buddha Machine. Este objeto fue creado por los artistas Zhang Jian y Christiaan Virant, para meditar. Es una pequeña caja de música de doce bits con nueve loops o melodías, control de frecuencia (pitch) y control de volumen. El Buddha Machine es un producto que ha sido desarrollado con el objetivo de recrear la experiencia de la meditación budista a través del uso de loops, es decir, archivos de audio que se repiten dentro de una composición, de forma tal que el final y el principio 
de la secuencia se encuentran en el mismo punto. Pero su característica más importante es la de brindar al usuario la posibilidad de sentir que tiene control sobre dichas melodías, a partir de su modificación y creación de ambientes musicales propios, ello por medio de la implementación de un control de frecuencia (el cual permite la variación en la velocidad o frecuencia del loop). El control de frecuencia genera mayor placer en el usuario desbloqueando infinitos mundos escondidos dentro de esta pequeña caja. En lugar de contar sólo con los nueve loops originales, el usuario cuenta con la opción de versiones más lentas o de baja frecuencia, así como versiones más rápidas y de alta frecuencia. "Cada loop se vuelve masivamente variable y explorar cada uno de ellos revela nuevos elementos, nuevas emociones, aporta nuevas experiencias al usuario y acaba siendo una fascinante creación ambiental" (Stephen, 2009). El Buddha Machine es muestra de que un producto no necesita ser complejo, siendo su principal atractivo la casi nula cantidad de funciones. El producto parece expresar un anhelo por la simplicidad y toma de decisiones en nombre del usuario (Wagstaff, 2007). Ver Figura 3

Partiendo de la información previa se estableció el Buddha Machine como estímulo para llevar a cabo nuestro experimento.

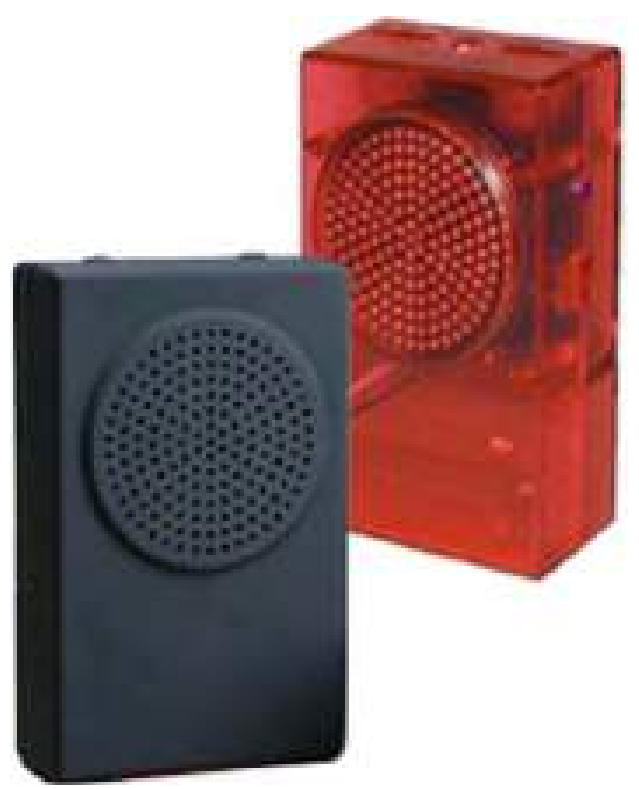


El producto es el estímulo y fue modificado para realizar el experimento. En el grupo de control, la perilla de control de frecuencia (pitch) estará habilitada, mientras que para el grupo de experimento estará inhabilitada. Esta decisión se tomó porque en las primeras etapas de la interacción con el producto se espera que el usuario sea capaz de crear y experimentar. Así, la posibilidad de contar con la perilla de control de frecuencia habilitada o inhabilitada, busca influir en el control percibido con el fin de modificar la experiencia de usuario de cada grupo al usar el producto. Es importante mencionar que antes de realizar el experimento no se corroboró que la manipulación de la perilla de control de frecuencia en el Buddha Machine, fuera capaz de generar una diferencia en la percepción de control en el usuario.

\section{Material}

- Buddha Machine negro (Grupo de control)

- Buddha Machine rojo

- Cuestionario de control percibido (Ver Anexo 1)

- 6 Tarjetas, cada una tenía impreso el nombre de las siguientes emociones: alegría, confianza, goce, desconfianza, aburrimiento y frustración.

\section{Procedimiento}

- Cada participante fue dirigido de forma individual a un espacio controlado.

- El participante fue informado sobre las características básicas del experimento.

- Cada sesión fue grabada con el consentimiento del participante.

- Para garantizar homogeneidad en la etapa previa a la interacción, cada uno de los participantes realizó una actividad de concentración mental (laberinto).

- Enseguida cada participante recibió una hoja con una serie de tareas a realizar, así como el producto con el que se llevaría a cabo la interacción.

- El participante contó con libertad de tiempo para interactuar con el objeto. Cada uno de ellos decidió el momento que completó las tareas y por consecuencia el final del experimento (Ver Figura 4). 
- Una vez completadas todas las tareas cada participante respondió el cuestionario de control percibido.

- Para la evaluación de la dimensión emocional se utilizó un método cualitativo, una entrevista la cual se desarrolla a partir de la elección de tarjetas con nombres de emociones. La pregunta guía de la entrevista fue: ¿por qué el producto estimuló una emoción específica? Los participantes recibieron seis tarjetas con nombres de emociones y eligieron aquellas que experimentaron con el producto. A partir de la elección, los participantes explican las razones por las que experimentaron dicha emoción, por ejemplo, sentí frustración porque no supe prender el producto. El método puede revisarse en Ortíz-Nicolás (2017).

- En promedio cada sesión tuvo una duración de trece minutos. Y de 1.7 minutos para el promedio de tiempo de interacción con el dispositivo.
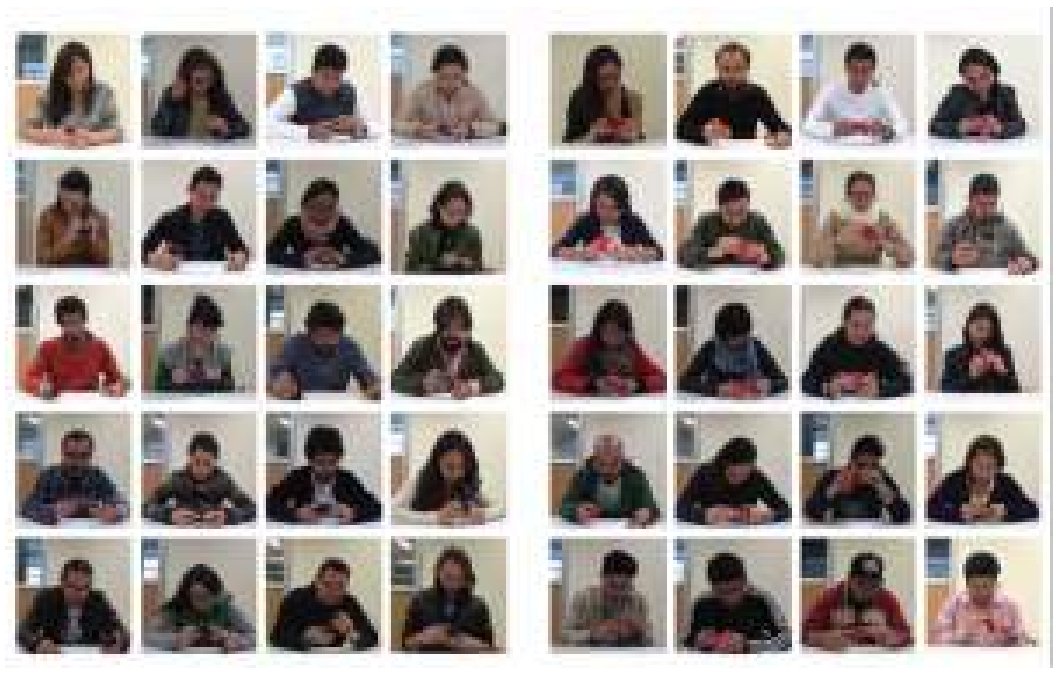

Figura 3. Participantes del estudio.

\section{Resultados}

Resultados Estímulo - Nivel de Control Percibido

Los resultados de los cuestionarios de ambos grupos fueron vaciados para llevar a cabo una prueba de correlación One-way ANOVA, la cual es capaz de señalar si dos variables (una independiente y otra dependiente) están relacionadas, con base en los valores de 
las medias de la variable dependiente y las compara con las categorías o grupos de la variable independiente. Es decir, señala si las medias entre dos o más grupos son similares o diferentes.

Este primer análisis cuantitativo buscó comprobar si el estímulo manipulado fue efectivo o no y permite determinar si existieron diferencias significativas entre el grupo A y grupo B con base en su nivel de control percibido a partir de la interacción con el Buddha Machine. De esta manera se podría generalizar que, si en un grupo hubo claramente mayor control percibido, la razón radicaría totalmente en la ausencia o presencia del botón de frecuencia. Esta primera prueba mostró un valor de correlación p-valor $=0.83$, lo que significa que no existe diferencia estadística significativa entre el nivel de control percibido entre el grupo A y el grupo B. En ambos grupos es posible observar una variación similar. Lo anterior implica que la presencia o ausencia del control de "pitch" no influyó en el nivel de control percibido, es decir, la manipulación del estímulo no funcionó. El nivel de control percibido en ambos grupos presenta una desviación estándar, $D E=0.74$, para el grupo $A$ y $D E=0.73$ para el grupo B. Ver Tabla 1.

\section{Estímulo}

Estímulo A

Buddha machine negro

Estímulo B

Buddha machine rojo

Muestra la relación entre el estímulo (control de pitch) y el nivel de control percibido, representada por medio del resultado de correlación One-way ANOVA para determinar el nivel de significancia entre estas.

Valor de correlación
$\mathrm{DE}=0.74$

$\mathrm{DE}=0.73$ $\mathrm{p}$-valor $=0.83$

(No existe diferencia significativa, no existe correlación).

Tabla 1. Prueba de efectividad del estímulo.

A partir de lo anterior se puede concluir que la manipulación del estímulo no funcionó, si bien dicha manipulación tenía como objetivo determinar de manera más clara las variables estudiadas, los resultados obtenidos aún son válidos para cumplir el objetivo de este 
estudio, ya que es posible analizar la relación del nivel de control percibido y emociones en todos los participantes, considerando que los datos son similares. De tal manera se integraron todos los datos en un solo grupo y se procedió a realizar un análisis general de la población total.

\section{Resultados Cuestionario de Control Percibido}

Considerando que creamos una base de datos única, decidimos realizar un tratamiento especial para aumentar el rigor. Con base en la teoría de Pekrun, donde se analizan tres principales niveles de control, la escala de control percibido empleada en la presente investigación permitió definir tres diferentes niveles de control percibido, de acuerdo con la siguiente categorización: cada ítem contó con cinco posibles respuestas que van de "completamente de acuerdo = 5" a "completamente en desacuerdo = 1", donde a mayor valor, menor es el nivel de control percibido. De la suma total de valores de cada participante se obtuvo la media y estos resultados fueron categorizados de la siguiente forma: para media igual a 1 o 2 el nivel de control percibido se define como "alto"; para media igual a 3 el nivel de control percibido es "medio"; y finalmente, para media igual a 4 o 5 el nivel de control percibido es "bajo". Ver Tabla 2

De acuerdo con los resultados obtenidos del total de los cuestionarios, de los cuarenta y dos participantes que realizaron la prueba, veintidós usuarios experimentaron un nivel de control percibido alto, diecisiete experimentaron un nivel de control percibido medio y tres, un nivel de control percibido bajo.

Los resultados de los cuestionarios de control percibido y emociones muestran que el total de emociones experimentadas y reportadas fue de 102: cincuenta y un positivas y cincuenta y un negativas.

Se puede identificar en la Tabla 2 que, de acuerdo con el nivel de control percibido, la presencia de emociones negativas o positivas cambia. De los cuarenta y dos participantes 
CONTROL PERCIBIDO, EMOCIONES Y EXPERIENCIAS

SATISFACTORIAS

\begin{tabular}{|c|c|c|c|c|c|c|c|}
\hline ID & Nivel de control percibido & Alegría & Confianza & Goce & Frustación & Aburrimiento & Desconfianza \\
\hline 1 & Alto & 1 & 1 & 0 & 0 & 1 & 1 \\
\hline 2 & Alto & 0 & 1 & 0 & 0 & 1 & 0 \\
\hline 3 & Medio & 0 & 0 & 0 & 1 & 0 & 1 \\
\hline 4 & Alto & 1 & 0 & 1 & 0 & 0 & 1 \\
\hline 5 & Medio & 0 & 0 & 1 & 0 & 0 & 1 \\
\hline 6 & Medio & 1 & 0 & 1 & 1 & 1 & 1 \\
\hline 7 & Medio & 0 & 0 & 0 & 1 & 0 & 1 \\
\hline 8 & Medio & 0 & 1 & 0 & 0 & 1 & 1 \\
\hline 9 & Alto & 0 & 0 & 0 & 1 & 1 & 1 \\
\hline 10 & Medio & 0 & 1 & 0 & 0 & 0 & 1 \\
\hline 11 & Alto & 1 & 0 & 1 & 1 & 1 & 0 \\
\hline 12 & Bajo & 0 & 0 & 0 & 1 & 0 & 1 \\
\hline 13 & Medio & 1 & 1 & 0 & 1 & 0 & 1 \\
\hline 14 & Alto & 0 & 1 & 0 & 0 & 0 & 1 \\
\hline 15 & Medio & 0 & 0 & 0 & 1 & 0 & 1 \\
\hline 16 & Alto & 1 & 1 & 1 & 0 & 0 & 1 \\
\hline 17 & Bajo & 1 & 0 & 1 & 1 & 0 & 0 \\
\hline 18 & Alto & 1 & 0 & 0 & 0 & 0 & 1 \\
\hline 19 & Alto & 0 & 1 & 1 & 0 & 0 & 0 \\
\hline 20 & Alto & 0 & 0 & 1 & 0 & 1 & 1 \\
\hline 21 & Alto & 1 & 1 & 0 & 1 & 0 & 0 \\
\hline 22 & Alto & 0 & 0 & 1 & 1 & 0 & 1 \\
\hline 23 & Bajo & 0 & 1 & 1 & 0 & 0 & 0 \\
\hline 24 & Medio & 1 & 1 & 1 & 0 & 0 & 0 \\
\hline 25 & Alto & 1 & 0 & 0 & 0 & 0 & 1 \\
\hline 26 & Alto & 0 & 1 & 1 & 1 & 0 & 1 \\
\hline 27 & Medio & 1 & 1 & 1 & 0 & 0 & 0 \\
\hline 28 & Alto & 0 & 0 & 0 & 1 & 1 & 0 \\
\hline 29 & Medio & 0 & 0 & 1 & 0 & 0 & 1 \\
\hline 30 & Alto & 0 & 1 & 1 & 0 & 0 & 0 \\
\hline 31 & Medio & 1 & 0 & 1 & 0 & 0 & 0 \\
\hline 32 & Alto & 0 & 0 & 1 & 0 & 0 & 0 \\
\hline 33 & Alto & 0 & 1 & 1 & 0 & 0 & 0 \\
\hline 34 & Alto & 0 & 1 & 0 & 0 & 0 & 0 \\
\hline 35 & Medio & 0 & 0 & 0 & 1 & 1 & 0 \\
\hline 36 & Medio & 0 & 1 & 0 & 0 & 1 & 0 \\
\hline 37 & Medio & 0 & 0 & 0 & 0 & 0 & 1 \\
\hline 38 & Alto & 0 & 0 & 0 & 0 & 1 & 0 \\
\hline 39 & Medio & 0 & 0 & 0 & 1 & 0 & 0 \\
\hline 40 & Medio & 0 & 1 & 0 & 0 & 0 & 0 \\
\hline 41 & Alto & 1 & 1 & 0 & 0 & 0 & 1 \\
\hline 42 & Alto & 0 & 1 & 0 & 0 & 0 & 1 \\
\hline
\end{tabular}

Tabla 2. Cuestionario de control percibido y emociones.

veintidós experimentaron un nivel de control percibido alto y reportaron las siguientes emociones:

a Ocho experimentaron alegría

b Doce confianza

c Diez goce

d Cuatro frustración

e Seis aburrimiento y

f Once desconfianza. 
El análisis detallado por nivel de control percibido se presenta en la Tabla 3. A partir de estos resultados podemos ver que los resultados entre ambos grupos son bastante similares.

\begin{tabular}{ccccccccc}
$\begin{array}{c}\text { Control } \\
\text { percibido }\end{array}$ & $\begin{array}{c}\text { Número de } \\
\text { participantes }\end{array}$ & Alegría & Confianza & Goce & Frustación & Aburrimiento & Desconfianza \\
\hline Alto & 22 & 8 & 12 & 10 & 4 & 6 & 11 \\
\hline Medio & 17 & 5 & 8 & 5 & 10 & 5 & 10 \\
\hline Bajo & 3 & 1 & 0 & 2 & 3 & 0 & 2 \\
\hline
\end{tabular}

Suma de emociones experimentadas de acuerdo con el nivel de control percibido. El nivel de control percibido se divide en alto, medio y bajo. Y 6 emociones: alegría, confianza, goce, frustación, aburrimiento y desconfianza. Primero se muestra el total de participantes que experimentaron cada uno de los distintos niveles de control percibido, seguido por el número de participantes que de ese número, experimentó cada una de las emociones.

Tabla 3. Nivel de control percibido y emociones.

\section{Análisis estadístico Control Percibido-Emociones}

Lo resultados obtenidos de las cuarenta y dos pruebas fueron sometidos a una prueba de correlación One-way ANOVA, técnica utilizada para comparar las medias de dos o más muestras (utilizando la distribución F). En este caso dicha técnica permitió identificar si existe una relación significativa entre el nivel de control percibido (variable independiente) y el tipo de emoción experimentada (variable dependiente). Concretamente, se busca analizar si la media del número de emociones (negativas o positivas) varía según el nivel de control percibido experimentado por cada usuario.

Antes de llevar a cabo la prueba de correlación, se realizó un sondeo gráfico como ayuda visual en la interpretación de los resultados obtenidos. La Figura 5 sugiere que puede existir una liga entre el nivel de control percibido y el tipo de emoción experimentada, es decir, a mayor nivel de control percibido, menor número de emociones negativas. Se puede observar el mismo comportamiento en las emociones positivas. 


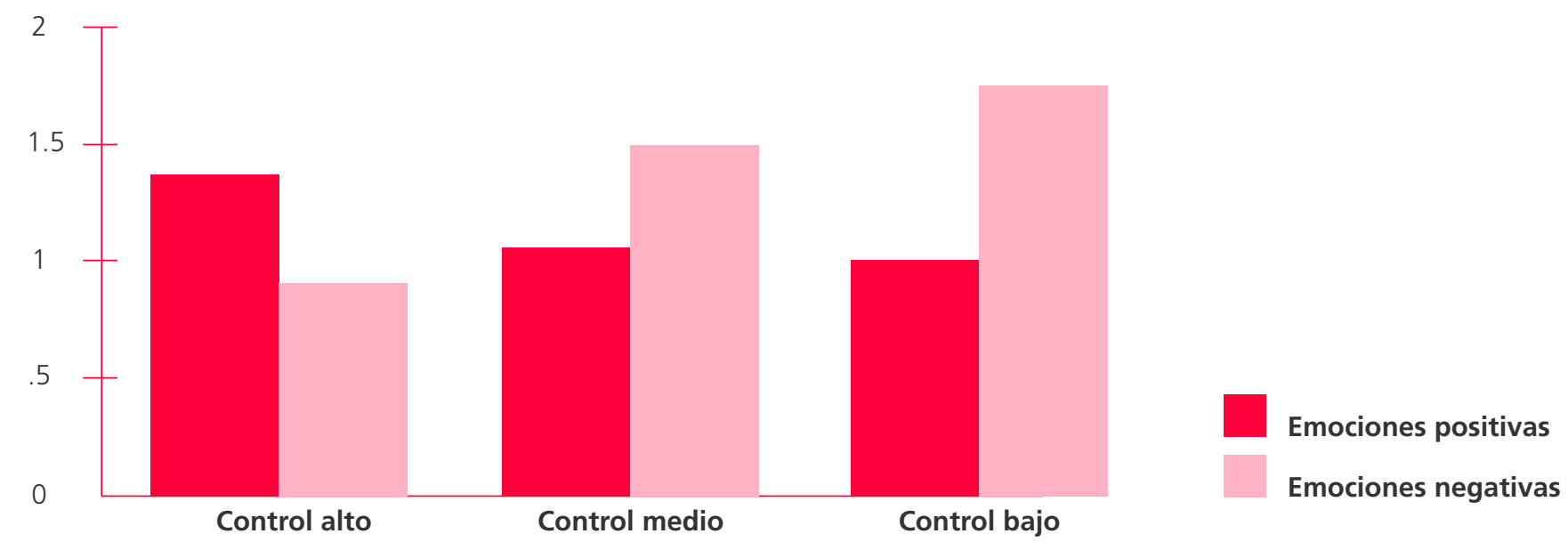

Figura 5. Media de emociones positivas y negativas en relación con el nivel de control percibido.

La Figura 5 muestra que el promedio de emociones positivas experimentadas aumenta de forma sutil junto con el aumento de control percibido. De igual forma, las emociones negativas experimentadas aumentan considerablemente mientras el nivel de control percibido disminuye.

Para poder corroborar este primer acercamiento se procedió a la aplicación de la prueba de correlación One-way ANOVA, con las características previamente señaladas. Los resultados se presentan en la Tabla 4.

Tipo de emoción

Valor de correlación

\begin{tabular}{clc}
\hline \multirow{2}{*}{ Control percibido } & Positiva (Alegría, confianza y goce) & p-valor $=0.60$ \\
& $\begin{array}{l}\text { Negativa (Frustación, aburrimiento y } \\
\text { desconfianza) }\end{array}$ & $p$-valor $=0.10$ \\
\hline
\end{tabular}

Prueba de correlación One-way ANOVA para identificar si existe una relación entre el tipo de emoción (positiva o negativa) y el nivel de control percibido experimentado. 
Los resultados muestran que no existe una correlación entre el nivel de control percibido y la valencia hedónica de las emociones (positivas o negativas). Sin embargo, aún es posible determinar si existe correlación entre el nivel de control percibido y cada emoción experimentada por separado. En la Tabla 5 se muestran los resultados obtenidos de la aplicación de la prueba de correlación One-way ANOVA para cada una de las emociones.

\begin{tabular}{ccccccc} 
& Alegría & Confianza & Goce & Frustación & Aburrimiento & Desconfianza \\
\hline Nivel de control & $\mathrm{p}$-valor & $\mathrm{p}$-valor & $\mathrm{p}$-valor & $\mathrm{p}$-valor & $\mathrm{p}$-valor & $\mathrm{p}$-valor \\
percibido & 0.90 & 0.21 & 0.39 & 0.002 & 0.57 & 0.79 \\
\hline
\end{tabular}

Prueba de correlación One-way ANOVA entre el nivel de control percibido y cada una de las emociones experimentadas. Se observa correlación entre el comportamiento del nivel de control percibido y la emoción frustación.

Tabla 5. Prueba de correlación para cada emoción.

A partir de los resultados obtenidos de las cuarenta y dos pruebas, fue posible identificar que solo la emoción "frustración" mostró una relación directa con el nivel de control percibido, esto sugiere que no se cuenta con pruebas suficientes para afirmar que sucede lo mismo con el resto de las emociones. En la sección análisis de resultados explicaremos esto.

\section{Resultados de la evaluación del factor emocional}

Para realizar el análisis de resultados se llevó a cabo la transcripción de las respuestas correspondientes a las emociones que cada uno de los participantes experimentó durante la interacción con el objeto. Además, se realizó el registro y conteo de cada emoción experimentada, con ello fue posible identificar cuáles fueron las emociones que tuvieron mayor presencia durante las intervenciones. Ver Tabla 5 
Como se ha mencionado ya, para la evaluación del factor emocional el participante eligió de las seis tarjetas de emociones (alegría, confianza, goce, frustración, aburrimiento, desconfianza), todas aquellas que experimentó durante la interacción y explicó las razones por las cuales experimentó tales emociones.

Los resultados obtenidos de la evaluación emocional se pueden ver en la Tabla 4 y muestran que de los cuarenta y dos participantes:
a Catorce experimentaron alegría
b Veinte experimentaron confianza
c Diecisiete experimentaron goce
d Diecisiete experimentaron frustración
e Once experimentaron aburrimiento
f Veintitrés experimentaron desconfianza

\section{Análisis de resultados}

\section{Análisis Estímulo-Control Percibido}

La manipulación del estímulo no fue efectiva, pero ha sido posible seguir analizando los resultados porque se está estudiando la relación control percibido y emociones; con el planteamiento del diseño original se buscaba ver la relación considerando la valencia (emociones positivas y control percibido versus emociones negativas y control percibido).

De acuerdo con los resultados de los cuestionarios, se identificó que a pesar de que en la mitad de los casos el estímulo no contaba con todas sus funciones, la percepción del usuario respecto a la realización de tareas fue similar tanto en aspectos positivos como negativos. Es decir, la ausencia del botón de frecuencia no influyó en la evaluación del producto. Esto puede explicarse por al menos dos razones, primero los participantes no recibieron una descripción detallada del producto y no era el fin, considerando que una condición para seleccionar a los participantes fue que no conocieran el producto. Segundo, algunas de las funciones tienen que ser descubiertas por el usuario (Stephen, 2009). De tal manera, 
al interactuar con el producto sin saber o tener claro los resultados de la interacción incidió en que los participantes creyeran que habían cumplido con todas las tareas. Se puede decir que para ambos grupos se cumplió la condición de que el objeto fue igual de desconocido.

\section{Análisis de nivel de control percibido - emoción, a partir de la Teoría de control-valor} Considerando que los resultados obtenidos no fueron los esperados, decidimos recurrir a la teoría de control-valor para hacer un análisis más profundo. En esta teoría las emociones están directamente ligadas con actividades logradas o satisfactorias; el logro puede definirse simplemente como la eficacia de actividades o de sus resultados, evaluados por algún estándar de calidad (Heckhausen, 1991). Esta teoría establece que un individuo experimenta emociones de logros específicos cuando se siente "en control de", o "fuera de control", por lo que la evaluación de control y valor es determinante en dichas emociones.

Generalmente, las emociones pueden estar influidas por diversos factores, como percepciones, evaluaciones, procesos fisiológicos, retroalimentación o expresiones faciales (Jacob-Dazarola et al, 2016). De los diferentes elementos que componen la teoría de control-valor, el control percibido es más importante que las actividades o logros mismos (Scherer, Schorr \& Johnstone, 2001).

Las emociones son determinados gracias a diferentes tipos de enfoque y marco de tiempo, donde el control percibido y el valor que el individuo experimenta tienen diferentes funciones. El valor se refiere a la evaluación que se hace, ya sea de la actividad o resultado (valor intrínseco), o de la utilidad de las acciones o resultados (valor extrínseco). Ambos tipos de valor se combinan en el ejercicio de evaluación y determinan si existe presencia de logro o fracaso desde la perspectiva del individuo.

A partir de esta información, la teoría control-valor conecta las evaluaciones con las emociones de logro y distingue tres tipos: 1) Emoción prospectiva de logro, 2) Emoción retrospectiva de logro y 3) Emoción en la actividad. Lo anterior se ilustra en la Tabla 6. 


\begin{tabular}{|c|c|c|c|}
\hline Objeto de enfoque & Valor & Control & Emoción \\
\hline \multirow[t]{5}{*}{$\begin{array}{l}\text { Resultado } \\
\text { Prospectiva }\end{array}$} & Positivo (Logro) & $\begin{array}{l}\text { Alto } \\
\text { Medio } \\
\text { Bajo }\end{array}$ & $\begin{array}{l}\text { Goce anticipado } \\
\text { Esperanza } \\
\text { Inseguridad }\end{array}$ \\
\hline & Negativo (Fracaso) & $\begin{array}{l}\text { Alto } \\
\text { Medio } \\
\text { Bajo }\end{array}$ & $\begin{array}{l}\text { Alivio anticipado } \\
\text { Ansiedad } \\
\text { Inseguridad }\end{array}$ \\
\hline & Positivo (Logro) & $\begin{array}{l}\text { Irrelevante } \\
\text { Propio } \\
\text { Otros }\end{array}$ & $\begin{array}{l}\text { Goce } \\
\text { Orgullo } \\
\text { Gratitud }\end{array}$ \\
\hline & Negativo (Fracaso) & $\begin{array}{l}\text { Irrelevante } \\
\text { Propio } \\
\text { Otros }\end{array}$ & $\begin{array}{l}\text { Tristeza } \\
\text { Vergüenza } \\
\text { Enojo }\end{array}$ \\
\hline & $\begin{array}{l}\text { Positivo } \\
\text { Negativo } \\
\text { Positivo / Negativo } \\
\text { Nulo }\end{array}$ & $\begin{array}{l}\text { Alto } \\
\text { Alto } \\
\text { Bajo } \\
\text { Alto / Bajo }\end{array}$ & $\begin{array}{l}\text { Goce } \\
\text { Enojo } \\
\text { Frustación } \\
\text { Aburrimiento }\end{array}$ \\
\hline
\end{tabular}

The Control-Value Theory: Basic Assumptions on Control, Values and Achievement Emotions (Teoría de control-valor: suposiciones básicas sobre el control, los valores y las emociones de logro de emociones) (Pekrum, 2006). Traducción propia al español.

Para clarificar los tres tipos de emociones de logro recurriremos a ejemplos extraídos directamente de las respuestas de los participantes. En la primera condición, emoción prospectiva de logro, se experimenta cuando un valor esperado, ya sea positivo (logro) o negativo (fracaso) tiene lugar. Si el control percibido es alto y el enfoque es positivo, se generará una alegría anticipada: "me divertí experimentando algo nuevo". Por otro lado, si el control percibido es alto pero el enfoque es negativo, se generará una expectativa de que el fracaso puede evitarse y, por lo tanto, un alivio anticipado: "no sabía lo que sucedería cuando lo iba a prender". En el caso que el control percibido es medio, implica que no hay certeza de éxito o fracaso, entonces se generará esperanza para el éxito y ansiedad para el fracaso: "no sabía si me iba a dar las funciones que requería para seguir las instrucciones". Por último, si el control percibido es bajo, en ambas condiciones (éxito y fracaso) se experimentará inseguridad, porque se cree que el éxito será difícil de alcanzar, es decir el fracaso es una certeza: "sabía que no iba a obtener lo que estaba esperando". 
En la condición 2, emoción retrospectiva de logro, el control percibido se atribuye de acuerdo con la importancia de las asignaciones causales de los logros, dónde alegría y tristeza corresponden a emociones independientes de control percibido, ya que el éxito conlleva a la alegría: "me relajó, me pareció intuitivo. Fue como jugar", y el fracaso a la tristeza: "no estaba clara la finalidad del objeto".

Las emociones orgullo, vergüenza, gratitud y enojo son dependientes del control percibido. Dichas emociones son ocasionadas por asignaciones causales, lo que implica que el individuo y otras personas o factores conllevan al logro: "me pareció que me estaban jugando una trampa", "sí supe hacerlo", "me sentí cómodo cuando leí las instrucciones".

Y finalmente, 3) Emoción durante la actividad depende del control percibido y del valor. Si el control percibido es alto y el valor positivo, se generará alegría. Si el control percibido es alto pero el valor es negativo, se experimentará enojo. Y por el contrario, si el valor es positivo o negativo, pero no hay suficiente control percibido o existen aparentes obstáculos que no pueden ser manejados, se experimentará frustración: "me frustré cuando no podía encontrar la melodía". Finalmente, si el valor no es positivo ni negativo, se experimentará aburrimiento: "cuando ví que el objeto no tenía más cosas".

Retomamos la teoría de control-valor porque ayudan a explicar los resultados obtenidos. En este experimento, pudimos observar que cuando el usuario experimenta un nivel de control percibido determinado como "alto", puede mostrar tanto emociones positivas como negativas, dependiendo del valor adjudicado a la interacción o tarea. Ver Tabla 7 


\begin{tabular}{|c|c|c|c|c|}
\hline $\begin{array}{c}\text { Testimonio } \\
\text { de participantes }\end{array}$ & Valor & $\begin{array}{l}\text { Nivel de control } \\
\text { percibido }\end{array}$ & $\begin{array}{c}\text { Tipo } \\
\text { de emoción }\end{array}$ & Emoción \\
\hline "Dije, ah ya lo prendí". & $\begin{array}{c}\text { Positivo } \\
\text { (Éxito) }\end{array}$ & Alto & $\begin{array}{l}\text { Emoción } \\
\text { prospectiva } \\
\text { de logro }\end{array}$ & Alegría \\
\hline $\begin{array}{l}\text { "Creo que estoy acostumbrado a } \\
\text { objetos más complejos. La tecnología } \\
\text { nos ha acostumbrado a que tengamos } \\
\text { más opciones". }\end{array}$ & $\begin{array}{l}\text { Ni positivo } \\
\text { ni negativo }\end{array}$ & Alto & $\begin{array}{l}\text { Emoción } \\
\text { retrospectiva } \\
\text { de logro }\end{array}$ & Aburrimiento \\
\hline $\begin{array}{l}\text { "Me parece absurdo que el botón } \\
\text { de encendido fuera éste y no éstes } \\
\text { (botón lateral), por la iluminación } \\
\text { de encendido". }\end{array}$ & $\begin{array}{l}\text { Negativo } \\
\text { (Fracaso) }\end{array}$ & Alto & $\begin{array}{l}\text { Emoción } \\
\text { durante } \\
\text { la actividad }\end{array}$ & Frustación \\
\hline
\end{tabular}

Los resultados del experimento no permiten establecer estadísticamente una correlación entre control percibido alto y emociones positivas o el proceso inverso. Sin embargo, fue posible apreciar de manera general, que la presencia de emociones positivas tiene una relación con otras emociones positivas, de igual forma las emociones negativas con otras emociones negativas (Ver Figura 5); el nivel de control percibido alto muestra una mayor presencia de emociones positivas sobre las negativas.

De la misma forma, podemos ver que en presencia de un nivel de control percibido bajo, puede haber tanto emociones positivas, como negativas dependiendo del tipo de valor asignado a tareas o momentos de la interacción. Ver Tabla 8 


\begin{tabular}{|c|c|c|c|c|}
\hline $\begin{array}{c}\text { Testimonio } \\
\text { de participantes }\end{array}$ & Valor & $\begin{array}{l}\text { Nivel de control } \\
\text { percibido }\end{array}$ & $\begin{array}{c}\text { Tipo } \\
\text { de emoción }\end{array}$ & Emoción \\
\hline $\begin{array}{l}\text { "Cuando comenzó a sonar, el hecho } \\
\text { de que salió la melodia". }\end{array}$ & $\begin{array}{l}\text { Positivo } \\
\text { (Éxito) }\end{array}$ & Bajo & $\begin{array}{l}\text { Emoción } \\
\text { prospectiva } \\
\text { de logro }\end{array}$ & Goce \\
\hline $\begin{array}{l}\text { "Pensé que iba a poder cambiar } \\
\text { más cosas". }\end{array}$ & $\begin{array}{l}\text { Ni positivo } \\
\text { ni negativo }\end{array}$ & Bajo & $\begin{array}{l}\text { Emoción } \\
\text { retrospectiva } \\
\text { de logro }\end{array}$ & Frustación \\
\hline $\begin{array}{l}\text { "Me costó trabajo encontrar como } \\
\text { se prende". }\end{array}$ & $\begin{array}{l}\text { Negativo } \\
\text { (Fracaso) }\end{array}$ & Bajo & $\begin{array}{c}\text { Emoción } \\
\text { durante } \\
\text { la actividad }\end{array}$ & Frustación \\
\hline
\end{tabular}

Análisis de emociones experimentadas, valor (éxito o fracaso) y nivel de control percibido bajo.

Tabla 8. Emoción, valor y nivel de control percibido bajo.

De esta forma, la teoría de control-valor explica cómo es posible que sean experimentadas tanto emociones positivas como negativas, en los diferentes niveles de control (bajo, medio y alto).

\section{El caso de frustración}

Nuestros resultados indican que hay una correlación entre control percibido y la emoción frustración, por lo que realizaremos un análisis detallado de esta emoción. El comportamiento de la emoción "frustración" puede observarse en la Figura 6.

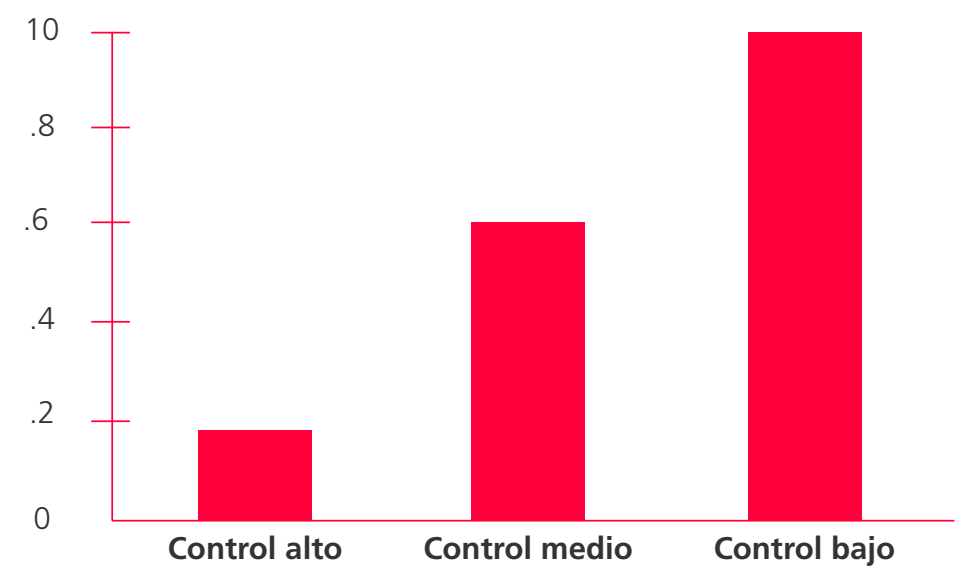


En la teoría de control-valor, las emociones de logro como lo indica Pekrun, se definen como emociones ligadas directamente a actividades o resultados de logro. Ejemplos de emociones de logro, son la alegría y el orgullo, las cuales pueden experimentarse cuando los estudiantes cumplen los objetivos académicos; y la frustración y la vergüenza, cuando fallan sus esfuerzos. El elemento clave de esta teoría estipula que los individuos experimentan emociones específicas de logro cuando se siente en control o fuera de control. Tanto los logros como las actividades mismas determinan dichas emociones, lo cual implica a su vez, que las evaluaciones de control y valor son los determinantes próximos más cercanos de dichas emociones.

Como ya se mencionó anteriormente, Pekrun distingue tres diferentes tipos de emociones de logro: emoción prospectiva de logro, emoción retrospectiva de logro y emoción de la actividad. A la emoción frustración se le sitúa en el tercer grupo de emociones y está ligada directamente con la actividad.

La Figura 4 muestra que la emoción de frustración fue frecuentemente reportada en los niveles bajos y medio y decrece en el nivel alto de control percibido. La teoría de control percibido explica que si al realizar una actividad existe poco control se experimentará frustración (Ver Tabla 6).

Con los datos cualitativos recabados confirmamos que en los grupos de nivel de control percibido bajo y medio donde no existió certeza de éxito o fracaso en el individuo o participante, se generó una esperanza enfocada en éxito y/o ansiedad ante el supuesto fracaso: "me gustan los aparatos sonoros, ya que lo tenía ahí no pude sacarle mucho [provecho]".

Con base en las emociones experimentadas y los datos cualitativos presentados anteriormente, se puede decir que no existió certeza de éxito debido a que el usuario no se sintió en control suficiente del objeto, ello debido a dos diferentes razones; una, cuando el participante adjudicó dicha experiencia a sí mismo, a su capacidad o nivel de influencia sobre el objeto: "se ve simple, pensé que sería fácil pero no pude". Y otra, cuando el participante 
adjudicó dicha experiencia a la funcionalidad del objeto; es decir, el objeto no le comunicó suficiente, la interacción fue confusa, y las funciones del objeto no fueron claras, especialmente la que se refiere al encendido: "deseaba prender el producto, pero no tiene la señalización del botón de encendido". Esta combinación de situaciones generó frustración.

\section{Discusión}

Como anteriormente se mencionó el objetivo de este estudio está dividido en dos partes. La primera fue determinar la correlación entre el nivel de control percibido, entendido como una necesidad psicológica, y las emociones experimentadas durante la interacción objeto-usuario, para poder definir si existe una correlación entre ambos, ya sea positiva o negativa. La segunda fue identificar si existe correlación entre el nivel de control percibido y la satisfacción general del usuario al interactuar con un producto.

La primera parte del objetivo la respondemos de la siguiente manera. Existe una liga entre el control percibido y las emociones, sin embargo, esta no es como se pensó, ya que existe un elemento determinante que no fue considerado al inicio de esta investigación, dicho elemento se refiere al "valor o motivación" (éxito o fracaso), el cual, en conjunto con el nivel de control percibido determinarán el tipo de emoción de logro que se experimentará. Es sabido que el mal funcionamiento de un objeto siempre ha existido y es claro también que puede influir en la experiencia del usuario. Es por ello que en la interacción es indispensable que el diseñador establezca una estructura obvia para el usuario, que apoye el razonamiento y la lógica detrás de las acciones o decisiones a tomar. Hancock y colegas (2011), se refieren a ello como un nivel de transparencia, capaz de influir la confianza del usuario, y esto puede lograrse a través de una mejor comunicación. Todo ello con el objetivo de ofrecer una mayor sensación de control que conlleve a la satisfacción del usuario. Aunque este enfoque es bueno para productos en los que se busca facilitar su uso a través del factor instrumental y usabilidad, se excluyen otras experiencias, como la diversión, en donde el azar y poco control están involucrados. Con base en nuestros resultados, entendemos lo que identificaron Hui y Bateson, que "el concepto de control 
percibido puede contribuir a explorar distintas formas de crear una experiencia de servicio más agradable" $(1991,181)$.

Nosotros tenemos una explicación más detallada. Si pensamos en el diseño de un cuchillo para chef, el diseñador muy probablemente buscaría generar una experiencia con la cual el usuario se sienta en control total de la herramienta, por las siguientes razones: el objeto debe permitirle enfocarse en la actividad de cocinar, en vez de poner atención al objeto en sí mismo. Por otro lado, si se busca diseñar un objeto que genere en el usuario la experiencia de juego, una experiencia lúdica que evoque la infancia, entonces sabemos que dicho producto va a provocar una cierta ilusión de poco control en el usuario, con características novedosas o funciones inesperadas y que a su vez logre evocar también emociones positivas, como alegría. Es decir, un nivel de control percibido bajo no sugiere forzosamente la evocación de una emoción negativa y a su vez podría conducir a la satisfacción del usuario. Aquí entran en juego las metas de la persona, si la persona no experimenta diversión probablemente la experiencia sea negativa. De tal manera, una conclusión de esta investigación es, el hecho de que un usuario se sienta en control no implica automáticamente la satisfacción de la persona, pues no necesariamente serán evocadas emociones positivas, de hecho, existe una posibilidad de que el usuario experimente tanto goce o confianza, como aburrimiento o frustración. Podemos asegurar entonces, que no todos los usuarios desean sentirse en control de cada producto con el que interactúan; para algunos resultará más agradable la experiencia aun cuando se sientan sin control. Con base en lo anterior, podemos responder el segundo punto de nuestro objetivo. Nuestros resultados indican que el control percibido impacta en la satisfacción cuando los productos involucrados son altamente utilitarios. Esto puede ser un punto de reflexión para el diseñador, quien puede considerar el nivel de control que debe incluir en la propuesta de diseño considerando la tarea a desarrollar y el tipo de experiencia que se busque ofrecer al usuario, así se podrán tomar en cuenta factores y características que faciliten dicho propósito.

Otra contribución de este estudio es el método análisis entre el control percibido, que incluye el factor "valor" (éxito o fracaso), y el tipo de emoción experimentada (positiva o 
negativa) en el usuario a partir de la teoría control-valor. Por medio de esta teoría pudimos explicar con mayor profundidad los factores que influyen tanto en el nivel de control percibido, como en la respuesta emocional. Esto fue posible porque se consideró el factor tiempo; la temporalidad sugiere tres tipos de emoción: emoción prospectiva de logro, emoción retrospectiva de logro y emoción en la actividad. Está tipología podría ser implementada para hacer el análisis cualitativo de las emociones más profundo. Por ejemplo, Desmet identificó que la actividad puede estimular una emoción y Ortíz-Nicolás (2014) reportó que el resultado de la actividad también estimula emociones. Esto coincide con la emoción en la actividad y la retrospectiva de logro, respectivamente.

Siguiendo el análisis detallado de las causas o razones que estimularon una emoción en particular, presentamos las causas identificadas a partir de los resultados de este estudio. Como mencionamos anteriormente, el nivel de control percibido no implica un cierto tipo de emoción absoluta, es decir, aquella persona que percibe un bajo control sobre el producto podría experimentar tanto goce como frustración, pues esto depende del fin que busque el usuario. Los factores que determinan la respuesta emocional son varios, pero su relación con el control y valor de logro es clara. Dicha relación permite tener una perspectiva más clara respecto a los posibles escenarios que surgirán a partir de la interacción de un individuo con un objeto específico.

El análisis de los factores que desencadenan una emoción permite entender una dimensión de la experiencia con un objeto a partir de factores personales y externos que desencadenaron en él ciertas emociones, así como la relación control-valor en cada uno de los casos.

En la Tabla 9 se muestran detalladamente los factores más recurrentes que evocan emociones positivas o negativas específicas y cómo ambos se relacionaron con el nivel de control percibido del usuario. Para realizar el análisis recurrimos a los seis factores básicos que evocan una determinada emoción en el usuario, que son: el objeto, lo significado, persona o usuario, otros, actividad e interacción, identificados por Desmet (2012), y a los otros dos identificados por Ortíz-Nicolás, (2014). El resultado de la actividad, por ejem- 
plo, crear una composición musical con el Buddha Machine que le agrade al usuario, en comparación a sólo explorar el producto. En el caso de un evento, el ejemplo sería la compra de Buddha Machine.

\begin{tabular}{|c|c|c|}
\hline $\begin{array}{l}\text { Nivel de control } \\
\text { percibido }\end{array}$ & $\begin{array}{l}\text { Factor potencializador } \\
\text { del nivel de control percibido }\end{array}$ & $\begin{array}{c}\text { Emoción } \\
\text { desencadenada }\end{array}$ \\
\hline \multirow{5}{*}{ Alto } & $\begin{array}{l}\text { Persona o usuario (Logro personal u orgullo) } \\
\text { "Cuando logré encenderlo". }\end{array}$ & Alegría \\
\hline & $\begin{array}{l}\text { Otros (Instrucciones) } \\
\text { "Al leer las instrucciones pude encender el objeto". }\end{array}$ & Alegría \\
\hline & $\begin{array}{l}\text { Interacción (Facilidad de uso) } \\
\text { "Me pareció fácil de usar". }\end{array}$ & Confianza \\
\hline & $\begin{array}{l}\text { Significado / Símbolo (Familiaridad) } \\
\text { "Tuve que remontarme alos radios viejos para saber que se prendía con el botón de volúmen". }\end{array}$ & Confianza \\
\hline & $\begin{array}{l}\text { Persona o usuario (Logro personal u orgullo) } \\
\text { "Porque ya le había agarrado la onda". }\end{array}$ & Confianza \\
\hline \multirow[b]{2}{*}{ Medio } & $\begin{array}{l}\text { Actividad o resultado de la interacción (Música) } \\
\text { "Hubo melodías que me agradaron". }\end{array}$ & Alegría \\
\hline & $\begin{array}{l}\text { Interacción / Actividad (Expectativas) } \\
\text { "No le vi mucha utilidad". "Cuando vi que el objeto no tenía más cosas, } \\
\text { pensé que iba a hacer algo diferente" }\end{array}$ & Aburrimiento \\
\hline \multirow{3}{*}{ Bajo } & $\begin{array}{l}\text { Significado / Interacción (Juego, actividad lúdica) } \\
\text { "Me sentí como un niño con juguete nuevo". } \\
\text { "Fue divertido estar jugando con los botones". "Fue como jugar". }\end{array}$ & Goce \\
\hline & $\begin{array}{l}\text { Interacción (Funciones / botones) } \\
\text { "No podía encontrar la melodía". "No sabía como prenderlo". } \\
\text { "No es intuitivo". "No lo podía prender, pensé que no iba a poder". } \\
\text { "No tuve mucho control". "Pensé que iba a poder cambiar más cosas". }\end{array}$ & Frustación \\
\hline & $\begin{array}{l}\text { Objeto (Novedad) } \\
\text { "Porque no sabía que era". "El objeto no me dice mucho". } \\
\text { "Porque era algo raro, algo nuevo". }\end{array}$ & Desconfianza \\
\hline
\end{tabular}

Resumen de factores que desencadenan emociones y la percepción de control en el usuario con base en algunos de los testimonios de los participantes.

Tabla 9. Factores que evocan emociones.

Con la información presentada en la Tabla 9 es posible identificar que la evaluación o valor efectivamente influye directamente en la experiencia de emociones positivas o negativas. Además, la información presentada en la tabla permite identificar características del producto que evocan ciertas emociones y que ofrecen al usuario mayor o menor sensación de control. Información como la que se presenta, puede ser una guía para el diseño de futuros 
productos, basados en la búsqueda de una determinada experiencia o de un determinado nivel de control percibido.

Por último, es importante mencionar que la experiencia es dinámica (McCarthy \& Wright, 2007; Hassenzahl, 2010; Ortíz-Nicolás \& Aurisicchio, 2011) y esto fue muy evidente en este estudio a través del proceso de interacción ligado a tareas específicas como: el encendido, la identificación de funciones o partes del producto, la manipulación directa, la contemplación o resultado, el éxito o fracaso de una tarea, etc. Ello implica que cada una de esas tareas o momentos de la interacción contribuyeron a la experiencia total, al control percibido general y a las emociones experimentadas. Si bien la experiencia integral es importante, porque es la evaluación general que hace la persona con el producto, quizá se pueda también hacer un estudio en el que se evalué cada tarea para saber cómo contribuye a la experiencia general y puede ser a su vez una estrategia de diseño.

En este estudio y gracias a las entrevistas realizadas, fue posible ver que la mayor parte de los participantes que experimentaron desconfianza, lo hicieron antes de la manipulación del producto, lo cual reitera que las personas se preparan o anticipan a la interacción con un producto (McCarthy \& Wright, 2007; Desmet, Ortíz-Nicolás \& Schoormans, 2008). Esta anticipación o preparación puede tener un efecto en la satisfacción general del usuario y por eso decimos que puede ser una estrategia de diseño, por ejemplo, un objeto de vidrio generalmente se trata con delicadeza, algo que puede considerar el diseñador es cómo se relacionará la persona con el objeto diseñado.

Considerando que la manipulación del estímulo falló en términos de control percibido, ahora tenemos una idea más clara de cómo podría funcionar dicha manipulación, por ejemplo, al comparar dos productos, uno en el que la funcionalidad sea clave y otro en dónde el azar esté involucrado. Probablemente con la comparación de estos dos objetos se podrían obtener resultados que logren confirmar plenamente lo que hemos identificado aquí. Por ello, se sugiere un nuevo estudio que permita analizar de forma más profunda la relación entre las emociones experimentadas, los factores que evocan tales emociones y el nivel de 
control percibido, en cada uno de los diferentes momentos o fases de la interacción. Las emociones experimentadas durante la interacción serán el resultado de tres momentos: prospectiva, actividad y retrospectiva. Y debido a que las causas adjudicadas a un logro pueden ser variadas, será común observar una mezcla de emociones, sobre todo cuando se analizan las emociones de retrospectiva. Ejemplo de ello es el siguiente, en el que un participante expresa las razones por las que experimentó: alegría ("...como un niño con juguete nuevo"), goce ("me divertí experimentando...), frustración ("cuando no podía encontrar la melodía"), aburrimiento ("Cuando ví que el objeto no tenía más cosa"), y desconfianza ("El objeto no me dice mucho"), todas durante la interacción.

Para un análisis más detallado y la posible identificación de los posibles patrones de respuesta control percibido-valor-emoción-factor, se propone identificar el nivel de control percibido en cada uno de los momentos que componen la interacción general. Si bien estos momentos pudieron ser identificados gracias a las entrevistas, no existió como tal, un instrumento que permitiera establecer con certeza estas tres etapas o momentos (prospectiva, actividad y retrospectiva) y sus comportamientos. La información estuvo enfocada a la actividad y retrospectiva, y a partir de estos datos fue posible comprobar que las evaluaciones de prospectiva tienen un papel clave durante la interacción misma y deben ser consideradas para poder observar el comportamiento general de las emociones de logro.

Más importante aún, para el análisis del control percibido en la interacción objeto-usuario, es indispensable comprender que el logro o satisfacción que surge como resultado de un intento por ejercer control será subjetivamente cierto o incierto: "estaba seguro de lo que tenía en las manos, dije es un radio", y será más o menos probable si existe incertidumbre. Cuando los participantes fueron cuestionados si consideraban que la interacción había sido satisfactoria, gran parte de ellos consideró que era difícil responder a dicha pregunta porque no tenían clara la funcionalidad del objeto. Para otros, la actividad fue satisfactoria porque llevaron a cabo las tareas requeridas. Hubo participantes que aun cuando disfrutaron de la actividad, no pudieron asegurar haber realizado las tareas satis- 
factoriamente. Por último, algunos participantes simplemente disfrutaron del objeto sin estar seguros de sí se estaban realizando las tareas de forma correcta o no.

La expectativa y valor corresponde a elementos que se combinarán de múltiples formas, lo que implica que ambos son necesarios para que una emoción de prospectiva sea generada. Por ejemplo, la ilusión y la ansiedad provienen de la derivación de un "resultado" incierto, y también podrían estar presentes de forma alternativa en situaciones de riesgo donde se busca obtener un logro.

Cuando analizamos por otro lado la retrospectiva, podemos ver que, ante el resultado de logro o fracaso, uno de los principales cuestionamientos es la causa de ello, ya sea la persona misma, otras personas o circunstancias externas. Ya que las causas de una idea de logro o fracaso pueden estar abiertas a interpretación, la satisfacción del usuario se verá afectada también dependiendo de lo que sea considerado como la causa de un logro: "batallé, tiene como un falso". Es posible ver que no todas las emociones de retrospectiva de logro dependerán directamente del nivel de control percibido, pero para las emociones que si son dependientes de éste la intensidad aumentará:

a En la medida en que la causa percibida haya contribuido al logro del resultado:

"sentí frustración porque deseaba prender el producto pero no tiene la señalización del botón de encendido, no sabía si serviría"

b De acuerdo con el valor subjetivo del resultado del logro: "me aburrí, no le vi mucha utilidad, no me divertí con el aparato".

Así también, cuando se analiza la actividad, que en este estudio se refiere a la manipulación o interacción directa con un producto mientras cierta tarea es llevada a cabo, el control y el valor consideran dicha acción excluyendo los resultados. La atención está en la actividad: "la melodía era agradable". El goce o disfrute durante la actividad puede ser esencial para que la experiencia de fluidez (flow) fomente la participación y la resolución creativa de problemas (Csikszentmihalyi, 2000). Tal emoción conllevará a que el usuario experimente entusiasmo en tareas desafiantes, así como estados más relajados cuando realice actividades rutinarias. 
Antes de cerrar la discusión nos gustaría explicar la relevancia de los resultados de este estudio para las industrias creativas. A partir de los resultados obtenidos consideramos relevante que sus especialistas evalúen el impacto que puede tener el control percibido al desarrollar espacios, productos, servicios o interfases. En los juegos mecánicos, por ejemplo, el control percibido es bajo, pues la persona compra un boleto solo para experimentar el juego. Por otro lado, manipular un reproductor de música generalmente involucra niveles altos de control percibido, pues el usuario busca reproducir las canciones de su preferencia. Si bien muchos de nuestros ejemplos recurren a productos de diseño industrial, se reconoce que ésta disciplina es parte de las industrias creativas (Castañeda-Rivera \& Garduño-Bello, 2017). Otra dimensión significativa de la economía creativa es la digital (Newbigin, 2010), considerar el nivel de control percibido en el desarrollo de objetos digitales (p.ej. software o aplicaciones) puede ser un factor de éxito o fracaso de las soluciones generadas. Finalmente, sugerimos que otras disciplinas que forman parte de las economías creativas, por ejemplo, el cine o la música, también involucran la dimensión de control percibido, probablemente los espectadores deciden asistir un concierto o ver una película precisamente porque no buscan tener el control, buscan ser sorprendidos, inspirados o solo quieren pasarla bien.

Por último, esta investigación se desarrolló a partir de un método mixto, es decir se emplearon tanto herramientas cuantitativas como cualitativas con el fin de que los datos obtenidos se complementaran y así cumplir el objetivo de la investigación. Una de las limitantes del método mixto y que influye directamente en la parte cuantitativa fue el empleo de muestreo por conveniencia (no probabilístico), lo que resultó en un sesgo muestral, es decir, la selección de los participantes de este estudio dependió de la accesibilidad, facilidad, rapidez y bajo costo para acceder a los participantes (Ver Teddlie \& Yu, 2007). Para poder generalizar los resultados sería necesario recurrir al muestreo probabilístico, de tal forma que se pueda garantizar no sólo la ausencia de sesgos, sino la obtención de información más amplia sobre los valores del parámetro estudiado en la población de la cual, dicha información haya sido extraída (Kish, 1995). 


\section{Conclusiones}

Si bien los resultados estadísticos no permitieron corroborar cada uno de los patrones que establece la teoría de control-valor, como resultado de la relación entre los elementos: control-valor-emoción. Gracias al análisis cualitativo del factor emocional fue posible identificar y confirmar algunos de estos comportamientos.

Es indispensable tener en cuenta que las emociones experimentadas durante la interacción son el resultado de tres momentos claves, cada uno de ellos con diferentes apreciaciones o perspectivas:

1 Prospectiva o antes de la manipulación directa

2 Actividad presente

3 Retrospectiva o resultados.

Por lo tanto, el análisis de las emociones experimentadas durante la interacción y en general la evaluación de la satisfacción del usuario, debe ser planteado a partir de la observación conjunta de dichos momentos.

Existen diversas teorías como se ha visto a lo largo de este estudio que sugieren la importancia que representa la satisfacción de las necesidades psicológicas del ser humano, como lo es el control percibido. Y es esencial entender que, como asegura Pavliscak (2014), la experiencia de usuario va mucho más allá de la mera facilidad de uso de un producto, se define a través de una serie de elementos, tanto las características del objeto, como percepciones y patrones mentales del usuario. Implica una idea de tiempo, así como un resultado esperado o inesperado. Además, es importante reconocer lo que menciona Hassenzahl (2010), la perspectiva de la experiencia y la experiencia de usuario no debe entenderse como definitivas, sino como un punto de partida que pueda lograr un cambio en la forma en la que son pensados los productos.

Una emoción surge no sólo por una exigencia, restricción o recurso del entorno, sino también por la yuxtaposición de ello con las motivaciones y creencias del individuo. Cada emo- 
ción surge de una situación o historia diferente y de la relación entre la persona y el medio ambiente. Cada interacción está acompañada de emociones, de factores que desencadenan dichas emociones, de percepciones y sentimientos, así como elementos externos que terminan afectando la percepción general del usuario.

Con el análisis cuidadoso de los elementos que determinan el tipo de interacción; elementos que sin duda se relacionan mientras la interacción se lleva a cabo y que van mucho más allá de la mera funcionalidad de un objeto, se podrá asegurar que los futuros productos, así como las interacciones con los mismos sean más satisfactorias y significativas. 


\section{Referencias}

Arnold, M. (1960). Emotion and Personality,

Psychological Aspects, 1. Columbia University Press: New York.

Csikszentmihalyi, M. (2000). Beyond boredom and anxiety. San Francisco, CA: Jossey-Bass.

Castañeda-Rivera, E. \& Garduño-Bello, B. (2017). Mapa de las industrias creativas en México. Proyección para CENTRO. Economía Creativa, 7, 117-162.

Desmet, P. (2012). Faces of product pleasure: 25 positive emotions in human-product interactions, International Journal of Design, 6 (2), 1-29.

Desmet, P.M.A. \& Hassenzahl, M. (2012). Towards happiness: Possibility-driven design. En Zacarias, M. \&de Oliveira, J.V. (Eds.), Human-Computer Interaction: The Agency Perspective. Springer, 3-27.

Desmet, P.M.A., Ortíz-Nicolás, J. C. \& Schoormans, J.P. (2008). Product personality in physical interaction. Design Studies, 29 (5), 458-477.

Dewey, J. (1967). Experiencia y educación. Buenos Aires: Losada.

Glass, D.C. \& Singer, J.E. (1972). Urban stress: Experiments on noise and social stressors. San Diego: Academic Press.

Hancock, P. A., Billings, D. R., Schaefer, K. E., Chen, J. Y., De Visser, E. J., \& Parasuraman, R. (2011). A meta-analysis of factors affecting trust in humanrobot interaction. Human Factors: The Journal of the Human Factors and Ergonomics Society, 53 (5), 517-527.

Hassenzahl, M. (2010). Experience Design: Technology for All the Right Reasons. Morgan and Claypool Publishers.

Hassenzahl, M. \& Diefenbacher S. (2012). Well-being, need fulfillment, and Experience Design. Workshop Designing Wellbeing, 11-12 Junio 2012, Newcastle, UK.
Heckhausen, H. (1991). Motivation and action. New York: Springer.

Hernández, D. (2009). Una perspectiva de las teorías de la emoción: hacia un estudio de las implicaciones de las emociones en la vida del hombre. Escuela de Ciencias Humanas, Universidad Colegio Mayor de Nuestra Señora del Rosario, 1-78.

Hui, M. K. \& Bateson, J. E. G. (1991). Perceived control and the effects of crowding and consumer choice on the service experience. Journal of Consumer Research, 18 (2), 174-184.

Jacob-Dazarola, R., Ortíz-Nicolás, J.C., \& Cardenas, L. (2016). Behavioral Measures of Emotion. In Meiselman H. (Ed.) Emotion Measurement (101-124). Amsterdam: Woodhead Publishing.

Behavioral Measures of Emotion (DOI: 10.1016/B9780-08-100508-8.00005-9) (PDF Download Available). Recuperado de: https://www.researchgate.net/ publication/301345166_Behavioral_Measures_of Emotion_DOI_101016B978-0-08-100508-800005-9 [accessed Aug 21, 2017].

Kidwell, B. \& Jewell, R. D. (2010). The motivational impact of perceived control on behavioral intentions. Journal of Applied Social Psychology, 40 (9), 2407-2433.

Kish L. (1995). Survey sampling. Nueva York: Wiley Classics Library.

Langer, E. J. \& Saegert, S. (1977). Crowding and cognitive control. Journal of Personality and Social Psychology, 35, 175-182.

Lazarus, R.S. \& Folkman, S. (1984). Stress, Appraisal and Coping. Nueva York: Springer.

Levenson, H. (1973). Multidimensional locus of control in psychiatric patients. Journal of Consulting and Clinical Psychology, 41, 397- 404.

McCarthy, J \& Wright, P. (2007). Technology as Experience, London: The MIT Press. 
Margolin, V. (2005). Las políticas de lo artificial [The politics of the artificial]. (G. Ubaldini, Trans) Editorial Designio. Primera edición, México. (Trabajo original publicado en 2002).

Mathur, A. (1998). Examining trying as a mediator and control as a moderator of intention-behavior relationship. Psychology \& Marketing, 15 (3), 241-259.

Newbigin, J. (2010). La economía creativa: una guía introductoria. Serie Economía Creativa y Cultural, British Council.

Ortíz-Nicolás, J.C. \& Hernández-López, I. (2008). Product relevant emotions in the Spanish language. The 6th International Conference on Design and Emotions, Hong Kong, China, October 6-9

Ortíz-Nicolás, J.C. (2014). Understanding and designing pleasant experiences with products. PhD dissertation, Imperial College London, London, The United Kingdom.

Ortíz-Nicolás, J.C. \& Aurisicchio, M. (2011). A scenario of user experience. In DS 68-7: Proceedings of the 18th International Conference on Engineering Design (ICED 11), Impacting Society through Engineering Design, Vol. 7: Human Behaviour in Design, Lyngby/ Copenhagen, Denmark, 15-19.08. 2011.

Ortíz-Nicolás, J.C. (2017). Identificando las causas que estimulan emociones específicas en la interacción persona-producto. En revisión Economía Creativa.

Pavliscak, P. (2014). Choosing the Right Metrics for User Experience. UX matters. Recuperado de: http://www. uxmatters.com/mt/archives/2014/06/choosing-theright-metrics-for-user- experience.php

Pekrun, R. (2006). The Control-Value Theory of Achievement Emotions: Assumptions, Corollaries, and Implications for Educational Research and Practice. Educational Psychology Review, 18, 315-341.
Pekrun, R., Frenzel, A. C., Goetz, T. \& Perry, R. P. (2007) The Control-Value Theory of Achievement Emotions: An Integrative Approach to Emotions in Education, 2, 13-36.

Peterson, C. \& Stunkard, AJ. (1992). Cognates of personal control: Locus of control, self- efficacy, and explanatory style. Applied and Preventive Psychology, $1,111-117$.

Ryan, R.M. \& Deci, E.L. (2000) Self-determination theory and the facilitation of intrinsic motivation, social development, and well-being. American Psychologist. 55 (1), 68-78.

Rotter, J. (1966). Generalized expectancies for internal versus external control of reinforcement. Psychological Monographs. 80 (1), No. 609.

Scherer, K. R., Schorr, A. \& Johnstone, T. (2001). Appraisal processes in emotion. Oxford, UK: Oxford University Press.

Sheldon, K. M., Elliot, A. J., Kim, Y., \& Kasser, T. (2001). What is satisfying about satisfying events? Testing 10 candidate psychological needs. Journal of Personality and Social Psychology 80 (2), 325-339.

Skinner, E. A. (1996). A guide to constructs of control. Journal of personality and social Psychology, 71, 549-570.

Solomon, Robert C. (2004). Thinking About Feeling. Oxford University Press: New York.

Sprott, D. E., Brumbaugh, A. M., \& Miyazaki, A. D (2001). Motivation and ability as predictors of play behavior in state-sponsored lotteries: an empirical assessment of psychological control. Psychology \& Marketing, 18 (9), 973-983.

Stephen, D. (2009). Buddha Machine II. Recuperado de: https://doctorvee.co.uk/2009/04/16/buddhamachine-ii/ 
Teddlie, C. \& Yu, F. (2007) Mixed Methods Sampling:

A Typology with Examples. Journal of Mixed Methods Research, 1, 77-100.

Wagstaff, J. (2007). The anti-iPod. The Wall Street Journal. Recuperado de: http://www.livemint.com/ Leisure/AfNc4dkfFtck7jY3SdqhkJ/The-antiiPod.html

Wallston, K. A., Wallston, B. S., Smith, S., \& Dobbins, C. (1987). Perceived control and health. Current Psychological Research and Reviews, 6, 5-25.

Ward, J. C. \& Barnes, J. W. (2001). Control and affect: the influence of feeling in control of the retail environment on affect, involvement, attitude, and behavior. Journal of Business Research, 54 (2), 139-144.

Wathieu, L., Brenner, L., Carmon, Z., Chattopadhyay, A., Wertenbroch, K., Drolet, A., Gourville, J., Muthukrishnan, A. V., Novemsky, N., Ratner, R., \& Wu, G. (2002). Consumer control and empowerment: a primer. Marketing Letters, 13 (3), 297-305.

White, R. (1959). Motivation reconsidered: The concept of competence. Psychological review, 66, 297-333. 